\section{YOU WILL NEVER GO BACK TO ANALOGUE IMPRESSIONS}

Recently launched in London's West End, eyeCAD-connect, developed by iDent, is the intelligent software component for the Epson Moverio Glasses. eyeCAD-connect together with an interactive touchpad enables practitioners to undertake digital impressions with efficiency and ease.

Instead of looking

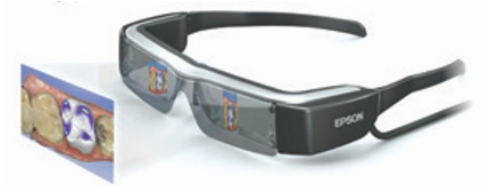

exceptional quality. The clear glasses have a large, bright display with a centred display in the field of vision.

The eyeCAD-connect software is the perfect connector system for your CAD-system and your Epson Moverio glasses. It will allow you to see digital impressions on your glasses in to and from the patient to the monitor when carrying out digital impressions, with eyeCAD-connect you can stay focused on the patient.

Epson Moverio Glasses deliver accurate and stable images with

real time within minutes.

Using eyeCAD-connect encourages correct posture in the practitioner.

To find out more about eyeCADconnect, visit http://eyecad-connect. com/index.html.

\section{ENABLE PATIENT TRIALS WITHOUT INFECTION CONCERN}

Until recently reusing a toothbrush that's been in a patient's mouth would have been anathema, however, this is exactly what you can do with Oral-B's Test Drive trial programme as they have developed specialised handles and replacement heads to ensure the safe trial of their toothbrush. A sealing insert within the head prevents saliva from entering the handle. To provide extra protection a disposable sheath covers the handle itself. After cleaning and disinfecting, the handle is then ready to be used again with a fresh head.

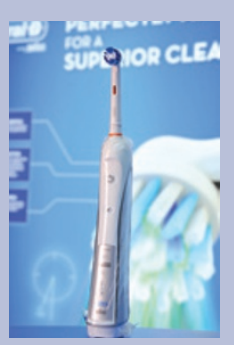

As consumers we can all be reluctant to embrace new technology unless we've experienced it and can see for ourselves the benefits afforded by its use. The new TestDrive trial programme allows both you and your patients to try Oral-B's power toothbrushes without having to worry about cross infection concerns. You can now experience the product without having to buy it. Moreover, you can ensure your patients are brushing their teeth properly.

Each TestDrive kit contains the specialised handle, 50 replacement heads, 55 sheaths and a cleaning a disinfection instruction manual. If you are interested contact your local representative or call 08702421850.

\section{A NEW QUALIFICATION IN LEADING WITH INTEGRITY}

UMD Professional has announced the launch of a new course for dentists and managers, leading to the Institute of Leadership and Management's (ILM) Level 5 Certificate in Leading with Integrity, which has been designed by the ILM in conjunction with the Cass Business School.

This practical three-day course provides a foundation in leadership with particular focus on the importance of leadership styles, culture, values, and integrity, and the practical application of leadership skills within the dental context today. The course will be held over two days in London in March, and in Leeds in April; there is also a follow-up day which incorporates an assessment for the Certificate qualification.

Fiona Stuart-Wilson of UMD Professional said: 'This course is very relevant, given the CQC's increasing focus on the importance of leadership and the continuing spotlight on the ethical framework in which dentistry operates.'

For more information call 02082552070 or email anniewalker@umdprofessional.co.uk.

\section{CELEBRATE 31 YEARS OF A SUCCESSFUL LECTURE SERIES}

The 2016 Talking Points in Dentistry lecture series, presented by the Sensodyne brand, offers tailored sessions for different team members to maximise relevance for the whole dental team.

The personal and social impact of dentine hypersensitivity

Lecture one: for dentist, hygienists and therapists Professor Peter Robinson and Professor Barry Gibson Dealing with nervous patients

Lecture two: for dental nurses and other practice staff

Professor Tim Newton and Brid Hendron

This year's venues

$\begin{array}{lll}5 \text { May } & \text { Hastings Europa } & \text { Belfast } \\ 12 \text { May } & \text { Watford Colosseum } & \text { Watford } \\ 17 \text { May } & \text { GSK House Brentford } & \text { London } \\ 19 \text { May } & \text { ICC Birmingham } & \text { Birmingham }\end{array}$

Book your tickets now by visiting www.gsk-dentalprofessionals.co.uk.

If you can't make it to one of the venues above, this year a special bitesize video of the speaker's lectures will be available on the www.gsk-dentalprofessionals. co.uk website after the events.

\section{A HIGHLY INFORMATIVE RESOURCE FOR IMPLANT PATIENTS}

As pioneers in research, innovation and product development, DENTSPLY has been at the forefront of dental implant service delivery during the discipline's evolution over the last five decades.

DENTSPLY Implants now offers patient information through the innovative Dentists4Implants.com website, a comprehensive and highly informative resource ideal for any patient considering dental implant treatment.

Containing details of over 200 clinics across the UK that offer dental implant treatment, patients can find an implant dentist in their area and request an initial consultation. The website features an in-depth FAQ section and users can access downloadable brochures which cover the different indications for implants, such as treating fully edentulous patients, and how implants can be used to replace single or multiple missing teeth or failed bridges. Success stories can also be submitted to the website and viewed via patient quotes, videos and case studies.

For implant clinicians this patient-centric site is the perfect opportunity to promote their practice and available treatment options to the general public whilst illustrating individual reviews and recent success stories.

To find out more about Dentists4Implants or to discover how you can get involved contact your local Territory Sales Manager or call 08000723313. 